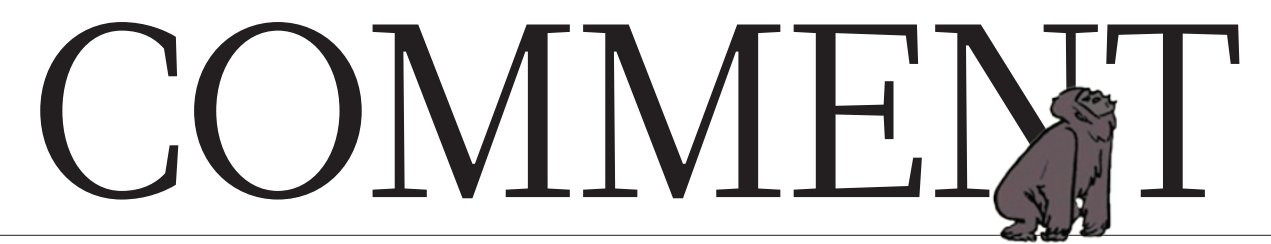

FACILITIES A call for new

observatories to lead an Arab astronomy renaissance $\mathbf{p . 1 6 1}$
LITERATURE Robert Macfarlane reflects on the resurgence in nature writing $\mathbf{p . 1 6 6}$
BIOGRAPHY Graphic novel brings female primatology greats to teens $\mathbf{p . 1 6 9}$
CONSERVATION Drought is

destroying Caatinga scrub forest in Brazil p.170

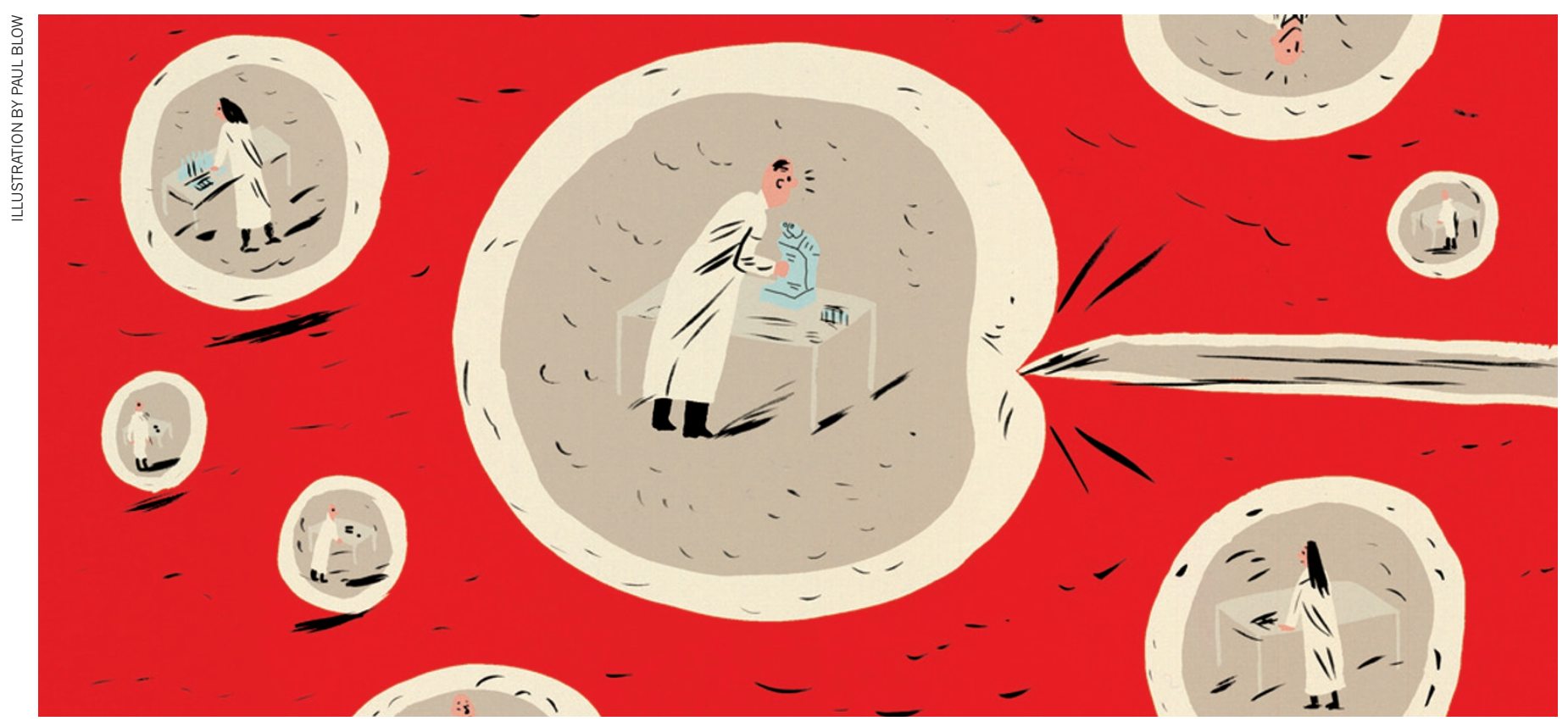

\title{
Stem-cell researchers must stay engaged
}

\section{Recent developments have rekindled the ethical debate over human cloning. This is no time for complacency, caution Martin Pera and Alan Trounson.}

$\mathrm{L}$ ast month, news ricocheted around the world that reproductive biologist Shoukhrat Mitalipov and his colleagues at the Oregon Health and Science University in Portland had used cloned human embryos to produce stem-cell lines specific to individual patients ${ }^{1}$. Although critics have since raised some problems with the paper, a preliminary enquiry indicates that the conclusions of the work still stand (see Nature http://doi.org/mnk; 2013).

This formidable technical feat is potentially a key step towards developing replacement tissues to treat disease. Media coverage of the paper has also rekindled long-standing controversies about human cloning, the use of human eggs and the destruction of human embryos. The achievement is a timely reminder that scientists must remain actively engaged in discussions about the ethics of using human embryos for research in cell biology and regenerative medicine.

More than 1,000 embryonic stem (ES) cell lines have now been established worldwide. There has also been an exponential increase in the use of induced pluripotent stem (iPS) cells - a type of stem cell that can be made from reprogramming the cells of body tissues, such as the skin or blood, back to the embryonic state. As a result, many people question whether there is still a need to obtain ES cells from the 'spare' human embryos that are surplus to those needed for in vitro fertilization. In recent months, it seemed as if stem-cell research had finally moved on from the uncertainty over funding and career prospects that has dogged it since 1998. Indeed, a prominent lobbying group for human ES-cell research, the Coalition for the Advancement of Medical Research in Washington DC, closed its doors last month (see go.nature.com/teedqq).

We believe, however, that enduring public concerns will inevitably resurface as stemcell biology progresses. Also, new ethical challenges will need exploring - such as whether it is justifiable to produce human reproductive cells (or gametes) from iPS cells, and what they should be used for.

To ensure that rational discussion among scientists, policy-makers, regulators and the public precedes the formulation of regulatory policy, individual researchers should try to avoid confronting the public with 
controversial scientific leaps out of the blue. Instead, scientists should gather to discuss the present and future course of human embryo research. They should also help to establish a formal programme for public consultation, similar to that led by two of the UK research-funding councils for synthetic biology. Ultimately, researchers should be prepared to continue arguing the case with governments and regulatory bodies when research on human embryos and ES cells is scientifically and medically merited.

\section{FUTURE PROOF}

Neither the current availability of numerous established ES-cell lines nor the increasing use of iPS cells rules out the possibility that human embryos will be needed in regenerative medicine in the future.

Clearly, the impetus for deriving new stem-cell lines from embryos has declined. More than 200 ES-cell lines are now on the US National Institutes of Health registry, meaning that anyone with the agency's funding can use them. Meanwhile, more than 1,200 lines are on the widely used International Stem Cell Registry, along with information about where to obtain them.

To produce new human ES-cell lines, researchers must negotiate a complex set of regulatory and compliance hurdles, obtain tens to hundreds of high-quality spare embryos, and do lab work that is labourintensive, time-consuming and expensive. With so many well-characterized lines available, there is little incentive to derive new lines using established technology. In fact, an analysis in 2009 revealed that around $70 \%$ of the published research on human ES cells is based on two cell lines ${ }^{2}$.

Yet the technology being used to derive and propagate cell lines does have shortcomings. For example, some cell lines are hard to renew and expand; about one-quarter of them develop genetic abnormalities in vitro after a routine period of cultivation ${ }^{3}$; and, in many cases, it is still very difficult to convert stem cells into fully mature functional cells, such as heart or liver cells.

Within the next decade, it is possible that technological improvements in the derivation and maintenance of ES cells will enable researchers to overcome deficiencies in culture systems. If this occurs, the use of new embryos to derive superior stem-cell lines might well be justified.

Similarly, it is unclear whether iPS cells will render ES cells redundant, despite the fact that the use of iPS cells has shot up in recent years (see 'Shifting preferences'). For example, there are still question marks over the genetic integrity of iPS cells and whether they differentiate into cells that are useful for therapeutic purposes as robustly as ES cells do. For instance, the skin cells of an adult, from which iPS cells can be derived, may have already

\section{SHIFTING PREFERENCES}

In recent years, research on human induced pluripotent stem (iPS) cells has grown rapidly, whereas studies of human embryonic stem (ES) cells seem to have plateaued. (Data include reviews and research articles.) 2,000

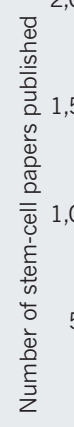
- Human ES cells Human iPS cells 1,500 $\frac{2}{n} 1,50$

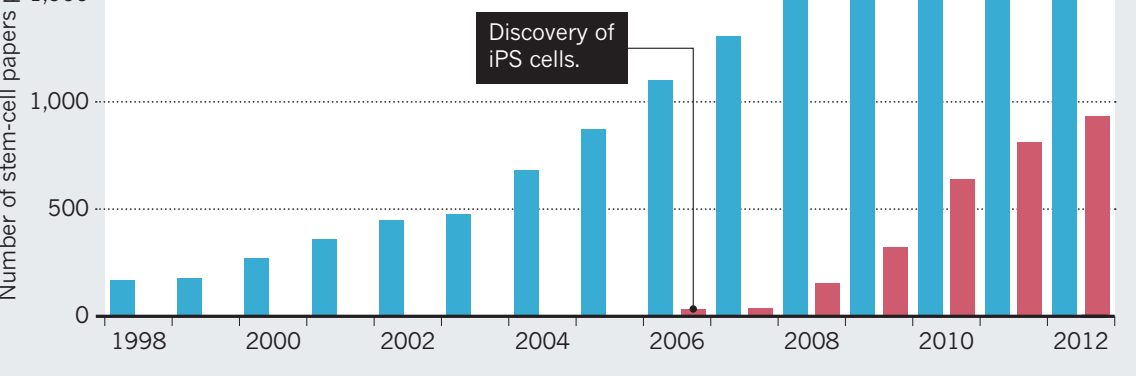

accumulated troublesome mutations, and the effects of reprogramming on the genetics of somatic cells are still being debated ${ }^{4}$.

Research groups in Japan and California are rapidly pushing studies on iPS-cell derivatives towards the clinic to treat agerelated macular degeneration (a major cause of blindness) and genetic skin disorders, among other diseases. But the therapeutic potential of iPS cells relative to that of ES cells will be known only when the safety and efficacy of both cell types has been thoroughly evaluated in preclinical animal models and in early-stage clinical trials.

Even if iPS cells do make ES cells obsolete, new directions in research using iPS cells could fuel more lively debate among the scientific community, regulators and the public than has been spurred so far by work on ES cells. Healthy mice, for example, have been produced from fertilized eggs derived from iPS cells ${ }^{5}$. If it becomes possible to make human gametes from iPS cells, these could have many uses: to study the basis of human infertility; to identify factors present in the egg that might enhance its reprogramming for stem-cell lines; to produce embryos in vivo and in vitro for treating human sterility; or even to genetically modify the germline to prevent disease.

These possibilities may be even more ethically challenging than the use of spare embryos from in vitro fertilization to make ES cells. So far, such prospects have hardly been mentioned in the public arena.

\section{CLONING REBORN}

One procedure that has generated much ethical controversy is somatic cell nuclear transfer (SCNT), or 'therapeutic cloning. Used by Mitalipov and his colleagues, this involves transferring the nuclear genome of an adult body cell, such as a skin or liver cell, into an unfertilized egg from which the nucleus has been removed. After 'tricking' the egg into becoming an embryo - by mimicking the chemical changes triggered by fertilization
- researchers can produce ES-cell lines that are genetically matched to the original donor.

Biologists initially envisioned SCNT as a way to produce patient-specific tissues needed for transplantations. Currently, it is permitted in only a handful of jurisdictions, including Britain, Australia, China, California, New York and Oregon. But until Mitalipov's breakthrough last month, no one had managed to convincingly produce ES cells from human cells using SCNT ${ }^{6}$.

The procedure is technically challenging, and a major stumbling block has been the need for numerous mature human eggs. In fact, interest in SCNT in humans waned substantially after the discovery of iPS cells, as measured by a decline in the number of SCNT papers and researchers working on it.

The findings of Mitalipov and his colleagues - or the future discovery of a way to derive hundreds of mature eggs from ES cells or iPS cells - could revive work on SCNT. Several biologists have argued that transferring nuclei from the somatic cells of humans to the eggs of another species, such as those from the frog Xenopus laevis, might be a powerful tool for understanding the reprogramming process in human cells ${ }^{7}$.

Even now, there is a compelling case for using SCNT-related technology in at least one clinical setting. Some mutations in mitochondrial DNA are associated with several potentially fatal disorders of the cardiovascular and nervous systems. Two studies from the past year show that the transfer of the haploid genome from an affected person into a healthy donor egg can prevent the inheritance of such mutations in cultured human ES-cell lines ${ }^{8,9}$. And Mitalipov and his co-workers point out that SCNT-derived cell products could be used to treat patients with mitochondrial diseases. Such proof-of-concept studies may represent the best hope yet for patients, or for women who are at risk of passing on a mitochondrial disease to their children.

We think that SCNT should be permitted to facilitate experiments in vitro, but 
not to develop a live human or humananimal hybrid. The use of SCNT-related technology to treat mitochondrial diseases does not involve cloning, but it does raise the question of whether it is acceptable for children to have three genetic 'parents': the mother who donates the egg nucleus, the father who donates the sperm nucleus and another woman who donates the mitochondrial DNA. The UK Human Fertilisation and Embryology Authority recommended in March that the government authorize the use of this technique to help these patients. We agree with this judgement.

Such possibilities need careful consideration and public consultation. We believe that the scientific community, which was forced to engage in ethical discussions in the early stages of stem-cell biology, should lead the way. As a first step, scientific academies such as the US National Academy of Sciences or the Australian Academy of Science should organize symposia to foster debate on the ethical ramifications of recent advances and possible new breakthroughs. Scientists should also engage with the public and the broader medical community; for instance, by collaborating with patient advocate groups such as the UK Juvenile Diabetes Research Foundation, and health-care providers such as the UK National Health Service. This would enable scientists to keep abreast of people's concerns, and to inform stakeholders of the realistic benefits and limits of their research and the ethical challenges it may bring.

The potential benefits of stem-cell research are immense. Prospects for transformative treatments for conditions such as macular degeneration, type 1 diabetes or Parkinson's disease are now on the horizon. But without first convincing governments, the public, and funding and regulatory bodies that all the possibilities have been thought through and evaluated, headline-catching results could create a backlash that unnecessarily delays the tremendous potential benefits of cell therapies. - SEENEWS \& VIEWS P.174

\section{Martin Pera is at the University of}

Melbourne, Australia. Alan Trounson is at the California Institute for Regenerative Medicine, San Francisco, California, USA. e-mails:mpera@unimelb.edu.au; atrounson@cirm.ca.gov

1. Tachibana, M. et al. Cell 153, 1228-1238 (2013).

2. Scott, C. T., McCormick, J. B. \& Owen-Smith, J. Nature Biotechnol. 27, 696-697 (2009).

3. The International Stem Cell Initiative Nature Biotechnol. 29, 1132-1144 (2011).

4. Ronen, D. \& Benvenisty, N. Curr. Opin. Genet. Dev. 22, 444-449 (2012).

5. Hayashi, K. et al. Science 338, 971-975(2012).

6. Grieshammer, U., Shepard, K. A., Nigh, A. \& Trounson, A. O. Nature Biotechnol. 29, 701-705 (2011).

7. Narbonne, P., Miyamoto, K. \& Gurdon, J. B. Curr. Opin. Genet. Dev. 22, 450-458 (2012)

8. Tachibana, M. et al. Nature 493,627-631 (2013).

9. Paull, D. et al. Nature 493, 632-637(2013).

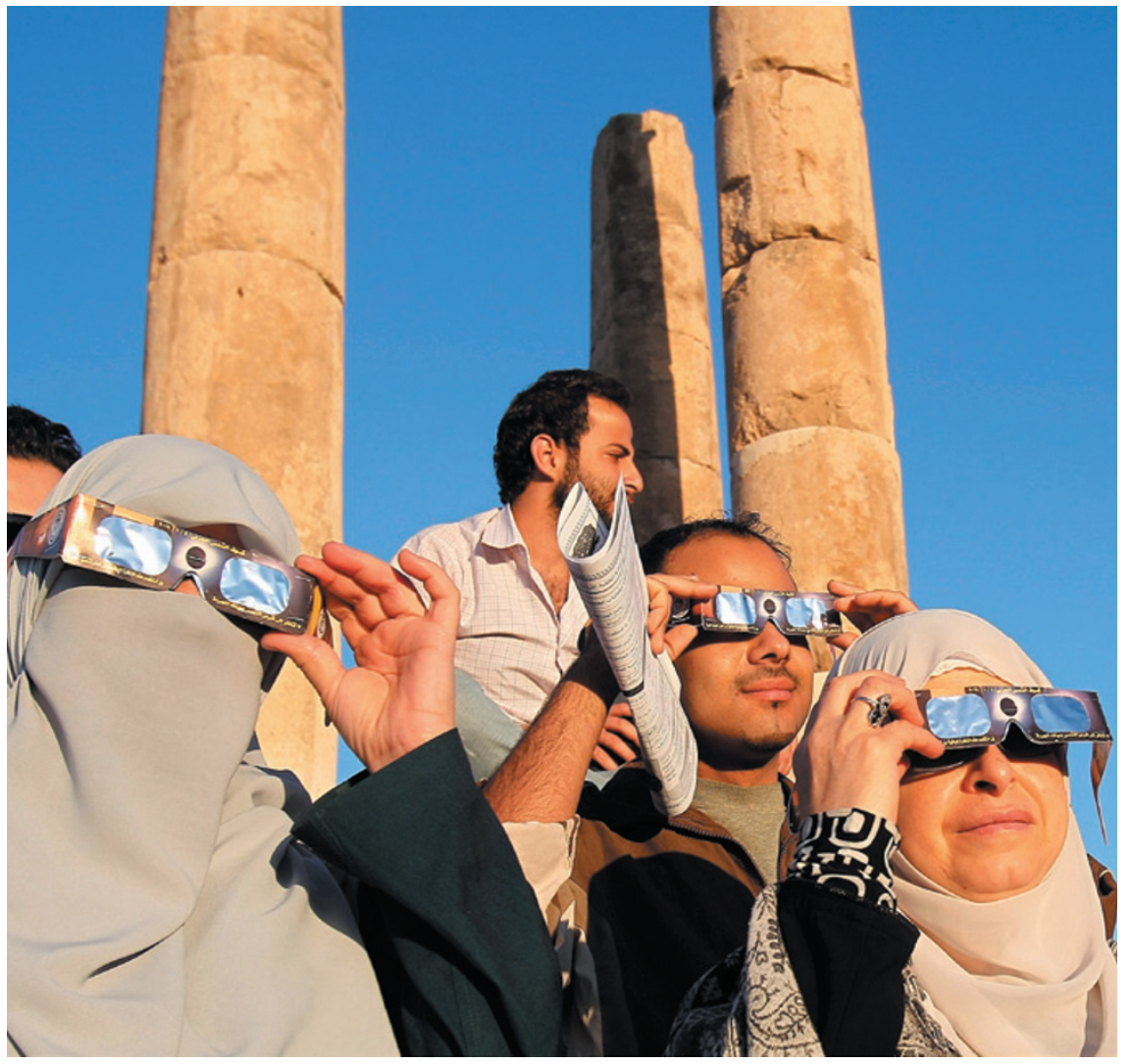

Observers in Amman, Jordan, watch the transit of Venus across the Sun in June 2012.

\section{Time for an}

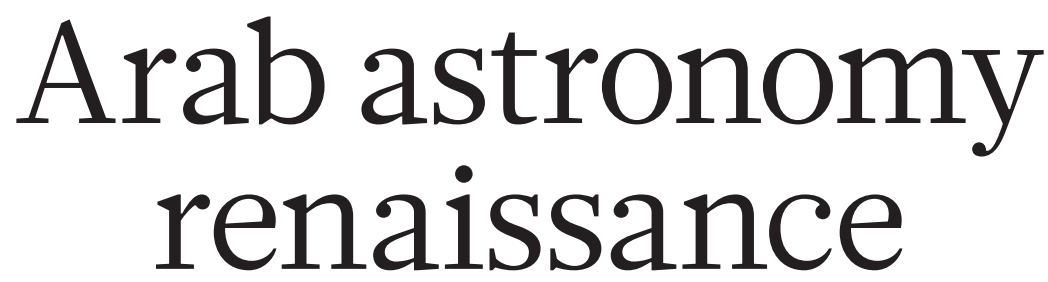

\section{Arab Muslim countries need a new generation of observatories to rejoin the forefront of the field, says Nidhal Guessoum.}

I

slamic astronomy enjoyed a golden age from the ninth to the sixteenth century AD. Great observatories in Baghdad, Damascus, Maragheh, Samarqand and Istanbul mapped the sky to set dates for religious and civil festivals and for astrology. Sophisticated calculations and models led to advances in mathematics.

Today, Arab astronomy barely registers on the world map. Scientific research is weak across the Arab world, and astronomy weaker still. Unlike countries of comparable gross domestic product per capita, such as Turkey, Israel and South Africa, most Arab nations are generating fewer than ten papers in the field each year, and these are hardly cited. Few sizeable telescopes are operational or planned.

The lagging state of astronomy is a paradox for a region where funding should not be a serious constraint, at least in the wealthier Gulf states. The region has several excellent observing locations above 2,000 metres that benefit from clear skies. Public fascination is strong, as shown by the many local amateur associations and large gatherings for astronomical events, such as eclipses, comet passages or the most recent transit of Venus across the Sun in June 2012. 